Original Research Paper

\title{
Antioxidant Activity, Anti-Inflammatory and Analgesic Effects of Caralluma europaea (Eddaghmouss) in Mice
}

\author{
1,2Aaziz Kebbou, ${ }^{1}$ Mehdi Ait Laaradia, ${ }^{1}$ Sara Oufquir, ${ }^{3}$ Ayoub Aarab, \\ ${ }^{1}$ Zineb El Gabbas, ${ }^{3}$ Hanane Rais, ${ }^{2}$ Abdelmajid Zyad and ${ }^{1}$ Abderrahman Chait \\ ${ }^{1}$ Laboratory of Pharmacology, NeuroBiology and Behavior, Department of Biology, \\ Faculty of Sciences Semlalia, Cadi Ayyad University, Marrakesh, Morocco \\ ${ }^{2}$ Team of Experimental Oncology and Natural Substances Cellular and Molecular Immuno-Pharmacology, \\ Faculty of Sciences and techniques, Sultan Moulay Slimane University, BeniMellal, Morocco \\ ${ }^{3}$ Laboratory of Immuno-Histo-Chimie, Anatomic Pathology Department, Mohamed VI University Hospital Center, \\ Faculty of Medicine and Pharmacy, Cadi Ayyad University, Marrakesh, Morocco
}

\section{Article history}

Received: 21-06-2019

Revised: 28-11-2019

Accepted: 20-12-2019

Corresponding Autor:

Abderrahman Chait

Laboratory of Pharmacology,

NeuroBiology and Behavior,

Department of Biology, Faculty

of Sciences Semlalia, Cadi

AyyadUniversity, Marrakesh,

Morocco

Email: chait@uca.ac.ma

\begin{abstract}
The aim of the current study is to evaluate the antiinflammatory, antioxidant and analgesic properties of ethanolic (100 and $200 \mathrm{mg} / \mathrm{kg}$, p.o.) and ethyl acetate extracts (100 and $200 \mathrm{mg} / \mathrm{kg}$, p.o.) of Caralluma europaea. Formalin-induced paw licking test, Acetic Acid induced Writhing Test and Hot-PlateTest were used to assess the analgesic activity. Xylene-induced ear edema test was used to evaluate anti-inflammatory activity of those extracts. In this work, the HighPerformance Liquid Chromatography technique (HPLC), allowed us to identify and quantify the main phenolic compounds present in ethanolic and ethyl acetate extracts. In vitro anti-oxidant propriety was evaluated using two methods, the 2,2-Diphenyl-1Picrylhydrazyl (DPPH) radical scavenging method and reducing power methods. The main phenols identified were Catechin (24\%) and quercetin (18\%) in ethanolic extract, while in the ethyl acetate extract, they were quercetin $(36 \%), \mathrm{P}$ coumaric $(30 \%)$ and 2-hydroxycinnamic $(25 \%)$. Analysis of our results had shown that Caralluma europaea extracts had exhibited a very potent analgesic activity. Percentage of Pain Inhibition (PPI) in the writhing test, $63.60 \pm 4.24 \%$ for the Ethanolic Extract (EE) $(200 \mathrm{mg} / \mathrm{kg}$, p.o.) and $65.39 \pm 3.27 \%$ for the Ethyl Acetate Extract (EAE). The PPI of early and late phase in the formalin test were respectively, $41 \%$ and $73 \%$ for EAE (200 mg/kg; p.o), $28 \%$ and $75 \%$ for EE. In the hotplate test, latency to the thermal stimuli was increased in a dose dependent manner after the administration of EE and EAE. However, the analgesic potential of EAE seems to be higher than EE. Both EE and EAE presented a significant in vitro redox potential and high antiinflammatory activity. Our results have shown that Caralluma europaea is rich in phenolic compounds and possesses an important antinociceptive, anti-inflammatory and anti-oxidant activity.
\end{abstract}

Keywords: Caralluma europaea, HPLC, Anti-Inflammatory, Analgesic, Antioxidant Activity

\section{Introduction}

Inflammation and pain are main preservative responses protecting the organisms counter physical, chemical and pathological alterations (Ezeja et al., 2011). The inflammatory response is produced by blood flow changes and escape of cells from the blood into the tissues due to the increased blood vessels permeability (Habashy et al., 2005).

Control of pain and inflammation is one of the main therapeutic goals (Ezeja et al., 2011). Currently, NonSteroidal Anti-Inflammatory Drugs (NSAIDs) and steroidal drugs are the principal medicament used for the treatment of inflammation and pain. However, several 
adverse effects such as liver impairment, manic depression, hypertension, muscle cramps and dizziness, decreased bone density, stomach ulcers, irregular menstruation, vision and allergic diseases are observed after long term use of these drugs (Murugesan and Deviponnuswamy, 2014; Brennan, 1984).

Due to the limited application and adverse effects of synthetic drugs, plant and natural product extracts are now being explored for their therapeutic properties.

Phenolic compounds of plant products are known to possess a wide range of physiological effects such as anti-inflammatory, anti-oxidant, anticancer and antibacterial properties which could constitute a source of therapeutics alternative. Therefore, the assessment of biological properties of plant extracts is of great importance for the discovery of novel drug candidates and validation of traditional medicine.

Caralluma europaea (CE) (or Apteranthes europaea Guss.) is a herb from Apocynaceae family (Meve and Liede, 2004) and widely distributed throughout Spain, Libya, Tunisa, Algeria and Morocco (Meve and Heneidak, 2005). Several medicinal uses including: Antidiabetic, antihyperglycemic, antiparasitic, antitrypanosomally, antiulcer, neuroprotective, antipyretic, anti-inflammatory, antinociceptive, antioxidant, anti-obesogenic and antiatherosclerosis activities were associated to various member of Caralluma genus properties (Zito et al., 2010; Wen et al., 2016). However, not all species have been tested for their biological activity. A review of literature of this plant proposed that Caralluma europaea has several properties such as antibacterial, antidiabetic and antioxidantactivity (Dutt et al., 2012). In addition, the anti-inflammatory and anti-nociceptive potential have never been investigated before.

The present investigation explores the antinociceptive, antioxidant and anti-inflammatory properties of Caralluma europaea plant extracts using in vitro and in vivo methods. The possible mechanism involved in the analgesic and anti-inflammatory activities was also investigated.

\section{Material and Methods}

\section{Animals}

In this study we used adult male Swiss mice (25$30 \mathrm{~g}$ ). Animals were provided from the Faculty of sciences Semlalia, Cadi Ayyad University. they were housed in cages at room temperature of $\left(25 \pm 2^{\circ} \mathrm{C} ; 12 / 12\right.$ h light/dark cycle). Mice were fed with standard food and water was offered ad libitum. All protocols used in this word respected the approved institutional procedures prescribed in the Scientific Procedures on Living Animals ACT 1986 (European Council directive: 86/609 EEC).

\section{Plant Material}

Fresh aerial parts pf $\mathrm{CE}$ were collected from the region of Beni Mellal, Morocco in April 2018. Voucher samples representing (CAE 023) were identified by Professor A. Ouhammou and were deposited in the Herbarium of the FSSM, Marrakesh, Morocco

\section{Crude Extract Preparation}

Extraction of the dried powdered Caralluma europaea aerial parts (100 g) was proceeded by using the maceration method with ethanol $(2 \mathrm{~L})$ for $24 \mathrm{~h}$, then filtered and re-extracted again by the ethanol for complete extraction. Extracts were then mixed and evaporated to give ethanol extract $(9.2 \mathrm{~g})$. The extract was dissolved in distilled water $(100 \mathrm{~mL})$ and transferred to the separatory funnel and portioned by hexane an ethyl acetate (Al-Jadidi and Hossain, 2018). The different extracted portions were dried using a rotary evaporator to give ethanolic and ethyl acetate crude extract $(6.1 \mathrm{~g})$.

\section{Acute Toxicity}

Mice were randomly grouped into control group and four treated groups $(0.5,1,2.5$ and $5 \mathrm{~g} / \mathrm{kg}$ body weight) for each extract, containing six animals each. All animals were provided with water ad libitum. In order to determine animals' death and toxic effects of changes in general behavior (tachycardia, vomiting, motor activity alteration, cramps, grooming, dyspnea, diarrhea and convulsions) (Shah Ayub et al., 1997; Bürger et al., 2005).

\section{Assessment of Total Phenolic Compounds, Tannins and Flavonoids Content in Caralluma europaea Extracts}

The FolinCiocalteau method was used in order to quantify the total phenolic compound content (Singleton et al., 1999). Briefly $20 \mu \mathrm{L}$ of extract was mixed with $100 \mu \mathrm{L}$ of Folin-Ciocalteau reagent and 1.16 $\mathrm{ml}$ of distilled water, then $300 \mu \mathrm{L}$ of sodium carbonate solution was added, then the mixture was incubated for $30 \mathrm{~min}$ at $40^{\circ} \mathrm{C}$. Measurement of mixture absorbance was made at $760 \mathrm{~nm}$. Results were expressed as gallic acid equivalents per Gram of Extract (GAE/g DM). The aluminum trichloride method was used to estimate total flavonoids content. Mixture was prepared using $0.5 \mathrm{~mL}$ of extract added to $0.5 \mathrm{~mL}$ of $2 \% \mathrm{AlCl}_{3}$ ethanol solution, then incubated at room temperature for $1 \mathrm{~h}$ before measurement of absorbance at $420 \mathrm{~nm}$. Results were expressed as catechin equivalents per gram of extract (CAT/g DM). In order to quantify Tannins, $100 \mu \mathrm{L}$ of extract was mixed with $1 \mathrm{~mL}$ of (Vanillin-MeOH) $4 \%$ and $0.5 \mathrm{~mL}$ of $\mathrm{HCl}$. The absorbance was measured at $550 \mathrm{~nm}$ after $15 \mathrm{~min}$ of incubation at room temperature 
(Xu and Chang, 2007). Results were expressed as catechin equivalents per gram of extract (CAT/g DM).

\section{HPLC analysis}

High-performance liquid chromatography 5KNEUER) equipped with a (K-1001) pump was used to the identification and quantification of phenolic compounds. $10 \mathrm{~mL}$ of Each Extract (EE and EAE) was injected over a C18 (Eurospher II 100-5), column temperature was maintained at $25^{\circ} \mathrm{C}$. The column was composed of acidified water (A) and acetonitrile (B). The flow rate was $1 \mathrm{ml} / \mathrm{min}$ and the total running time was $60 \mathrm{~min}$. Phenolic compounds identification was done by comparing their retention times with those of standards (Quercetin, Sinapicacid, Narginine, Caffeic acid, Ferulic acid, Rutin ...).

\section{Antioxidant Activity}

\section{DPPH Free Radical Scavenging Activity}

In order to assess the free radical-scavenging activity of Caralluma europaea extracts we used the stable free radical 2,2-diphenyl-1-picrylhydrazyl radical (DPPH), as described by Burits and Bucar (2000). Briefly, $50 \mu \mathrm{L}$ of different extract concentration were mixed with $2 \mathrm{~mL}$ of $60 \mathrm{mM}$ methanol solution of DPPH. Then absorbance of samples was measured at $517 \mathrm{~nm}$ after $20 \mathrm{~min}$ of incubation in the dark at room temperature. Blank solution was prepared using the same amount of methanol and DPPH. Quercetin and Butylated Hydroxytoluene (BHT) were used as positive control. Calculation of the inhibition of the DPPH (\%) was done using the following equation (Badakhshan et al., 2012):

$$
\left.I \%=\left[A_{\text {blank }}-A_{\text {sample }}\right) / A_{\text {blank }}\right] * 100
$$

where, $A_{\text {blank }}$ is the absorbance of the control and $A_{\text {sample }}$ is the absorbance of the test compound. The sample concentration providing $50 \%$ inhibition (IC50) was calculated from the graph by plotting inhibition percentages against sample concentrations.

\section{Reducing Power Assay}

As described by Oyaizu (1986), we assessed the reducing power of the EE and EAE. $1 \mathrm{~mL}$ of various sample concentrations was added to the phosphate buffer (2.5 mL, $200 \mathrm{mM}, \mathrm{Ph}$ 6.6) and potassium ferricyanide $(2.5 \mathrm{~mL}, 1 \%)$. The resulted solution was incubated for $20 \mathrm{~min}$ at $50^{\circ} \mathrm{C}$, after incubation period $2.5 \mathrm{~mL}$ of $10 \%$ Trichloroacetic Acid (TCA) was mixed with the solution and then centrifuged at $3000 \mathrm{rpm}$ for $10 \mathrm{~min}$. $2.5 \mathrm{~mL}$ of the upper layer solution was added to $2.5 \mathrm{ml}$ of distilled water and $0.5 \mathrm{~mL}$ of $0.1 \%$ ferric chloride $\left(\mathrm{FeCl}_{3}\right)$. Measurement of coloration formed by the reduction of $\mathrm{Fe}^{+}$at $700 \mathrm{~nm}$ was used to determine the sample concentration providing 0.5 of absorbance (IC50). BHT, ascorbic acid and quercetin were used as positive controls.

\section{Assessment of Pharmacological Activities}

\section{Antinociceptive Tests}

\section{Writhing Test}

Writhing test is used to evaluate mice response to the chemical nociceptive stimulus (Farouk et al., 2008). This test aims to study the peripheral nociceptive sensitivity in mice.

Treatment is carried out 30 minutes before the injection of acetic acid at a dose of $10 \mathrm{ml} / \mathrm{kg}$ of the mice weight. Following the intraperitoneal administration of acetic acid $(0.6 \%$ at $0.1 \mathrm{ml} / 10 \mathrm{~g}$ weight) (Farouk et al., 2008), animals were placed on plexiglass to observe the number of contortions made by the mice during a period of $30 \mathrm{~min}$.

The Percentage of inhibition (IP) of the nociceptive response is calculated. It is defined as follows:

$$
I=[(N C-N T) / N C] \times 100
$$

Where:

$N C$ : Number of contortions in the control group.

$N T$ : Number of contortions of a tested group.

\section{Formalin Test}

In the present study we used the method previously described by De Miranda et al. (2001). Briefly, $20 \mu \mathrm{L}$ of $2 \%$ formalin was Subcutaneously injected into the right posterior paw of mice. Each mouse was allowed to adapt the testing box for $5 \mathrm{~min}$ prior the formalin injection. nociceptive behavior was quantified as the total time spent in licking and/or biting the injected paw. The quantification of nociceptive behavior was made during two phases (Hunskaar and Hole, 1987) the early nociceptive response normally peaked $5 \mathrm{~min}$ after formalin injection and 15-30 min after formalin injection peaked the late nociceptive response representing the tonic and inflammatory pain responses, respectively. $30 \mathrm{~min}$ prior formalin injection, mice were pretreated orally with two doses of EE and EAE (100 mg/kg and $200 \mathrm{mg} / \mathrm{kg}$ ).

\section{Hot Plate Test}

This test consists of placing each mouse into a glass cylinder $(20 \mathrm{~cm}$ of diameter $)$ on a heated surface $\left(55 \pm 0.4^{\circ} \mathrm{C}\right)$. Treated mice received two doses orally of $\mathrm{EE}$ and EAE $(100 \mathrm{mg} / \mathrm{kg}$ and $20 \mathrm{mg} / \mathrm{kg})$. Negative control group received water orally at $0.1 \mathrm{ml} / \mathrm{g}$. Positive control group had received Morphine intraperitoneally at $10 \mathrm{mg} / \mathrm{kg}$. The latency time taken by the mouse to lick 
one of its paws or to jump is noted and considered as the time of the reaction. The duration of this test should not be longer than $20 \mathrm{sec}$ to avoid causing damage to the cutaneous tissue of the mice' paws (Farouk et al., 2008).

\section{Anti-Inflammatory Activity}

\section{Xylene Induced Mouse Ear Edema}

According to Shang et al. (2011) Acute inflammation was induced by topical application of $30 \mu 1$ of xylene on the anterior a posterior surfaces of the right ear. Six groups of adult Swiss albino mice were randomly assigned as follow: Control group (Saline solution $0.9 \%$ ), treated groups with EE and EAE (100 and 200 $\mathrm{mg} / \mathrm{kg}$, orally) and a group of diclofenac $(10 \mathrm{mg} / \mathrm{kg}$ i.p. $)$ were administered $45 \mathrm{~min}$ prior to the xylene application. Mice of each group were euthanized $30 \mathrm{~min}$ after xylene application and two ear punches $(6 \mathrm{~mm}$ diameter) were taken from each animal and weighted. Edema was estimated by comparing the weight of the right ear punch with the left ear indicated.

\section{Histological Examination}

For histological assessment, six samples of the inflamed ears from the control and treated groups were taken and fixed in formaldehyde (10\%). The fixed ear tissues were embedded in paraffin and cut into 3-4 $\mu \mathrm{m}$ sections. The slices were mounted on the glass slides, stained with Hematoxylin and Eosin (HE) for pathological studies as descripted by Kiernan (1999).

\section{Statistical Analysis}

Results were shown as means \pm S.E.M and the comparisons between the experimental groups were made using one Way ANOVA. The values were considered statistically significant when the P-value was less than 0.05 , statistical analyses were done using Sigma Plot 12.5 for Windows.

\section{Results}

\section{Acute Toxicity}

In this study the evaluation of in vivo test on mice for the acute toxicity of the two extract of $C$. europaea showed that the (LD50) is greater than $5 \mathrm{~g} / \mathrm{kg}$, in fact no mortality or signs of toxicity and no change body weight wasn't observed during the $48 \mathrm{~h}$ following single dose administration $(0.5,1,2.5$ and $5 \mathrm{~g} / \mathrm{kg}$ body weight) of each of the two Caralluma europaea extracts.

\section{Determination of Total Phenolic Compounds, Tannins and Flavonoids}

Phytochemical analysis Table 1 showed an important amount of total phenolics, flavonoids and condensed tannins in both extracts studied.

\section{HPLC Analysis}

The results of the HPLC technique allowed us to identify and quantify main phenolic compounds HPLC compounds of Caralluma europaea ethanolic (EE) and ethyl acetate (EAE). According to the HPLC chromatogram (Fig. 1), the ethyl acetate extract contained rutin, ferulic acid, caffeic acid, narginine, 2hydroxycinnamic, sinapic acid, P-coumaric acid and quercetin. The principal phenolic components of the ethyl acetate extract are respectively: Quercetin (36 mg EGA/100g DM), P-coumaric (30 mg EGA/100g DM) and 2-hydroxycinnamic (25 mg EGA/100 g DM).

While the Caralluma europaeaethanolic extract comprises: Ascorbic acid, catechic acid, vanillic acid, ferulic acid, caffeic acid, narginine, quinin, vanillin, 2hydroxycinnamic, sinapicacid, catechin, P-coumaric and quercetin (Fig. 2). Catechin was the major phenolic compound identified with (24 mg EGA/100g DM), followed by quercetin (18 $\mathrm{mg} \mathrm{EGA} / 100 \mathrm{~g} \mathrm{DM}))$. The concentrations of the main phenols identified in both extracts are presented in Table 2 and 3.

Table 1: Total phenolics, flavonoids and tannins content of ethanol extract and ethyl acetate extract of the Caralluma europaea (Mean \pm SEM).

\begin{tabular}{lll}
\hline & Ethyl acetate extract & Ethanol extract \\
\hline Total phenolic contents (mg GAE/g DW) & $14.84 \pm 0.58$ & $20.93 \pm 0.30$ \\
Flavonoid contents (mg/g DW) & $13.93 \pm 0.30$ & $10.19 \pm 0.63$ \\
Tannin contents (mg CE/g DW) & $2.47 \pm 0.01$ & $2.28 \pm 0.03$ \\
\hline
\end{tabular}

Table 2: The phenols amounts found in the ethyl acetate extract ranged from 1 to $37 \mathrm{mg}$ EGA/100 g DM

\begin{tabular}{lll}
\hline & Phenolic compounds & Concentrations (mg EGA/100 g DM) \\
\hline 1 & Rutin & 12,970 \\
2 & Furrulic acid & 13,908 \\
3 & Caffeic acid & 15,544 \\
4 & Narginine & 12,926 \\
5 & 2-hydroxycinnamic & 25,174 \\
6 & Sinapic acid & 18,296 \\
7 & P-Coumaric & 30,671 \\
8 & Quercitin & 36,186 \\
\hline
\end{tabular}




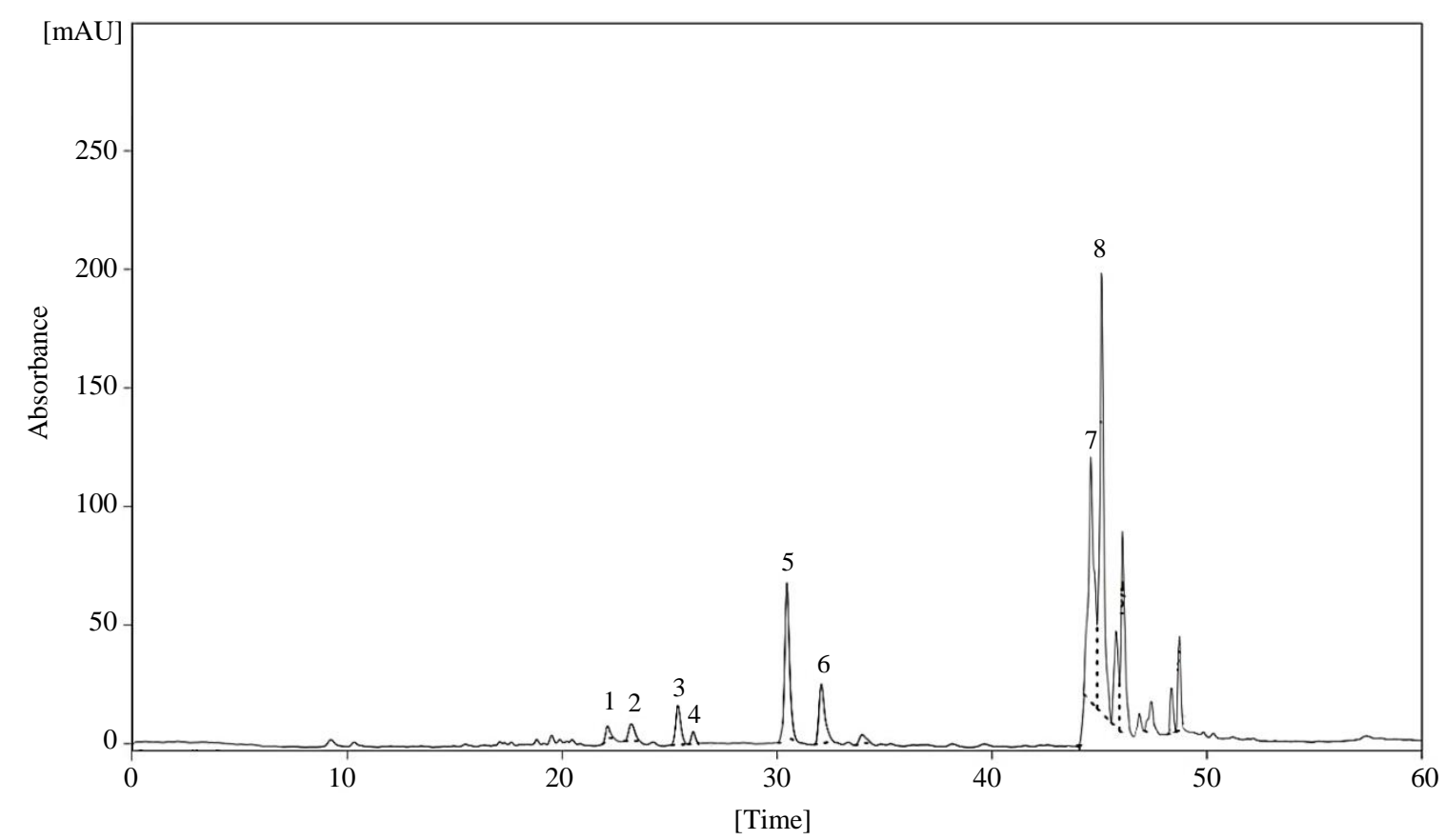

Fig. 1: HPLC chromatogram registered at $280 \mathrm{~nm}$ for the major phenolic compounds detected in the ethyl acetate extract of $C$. europaea

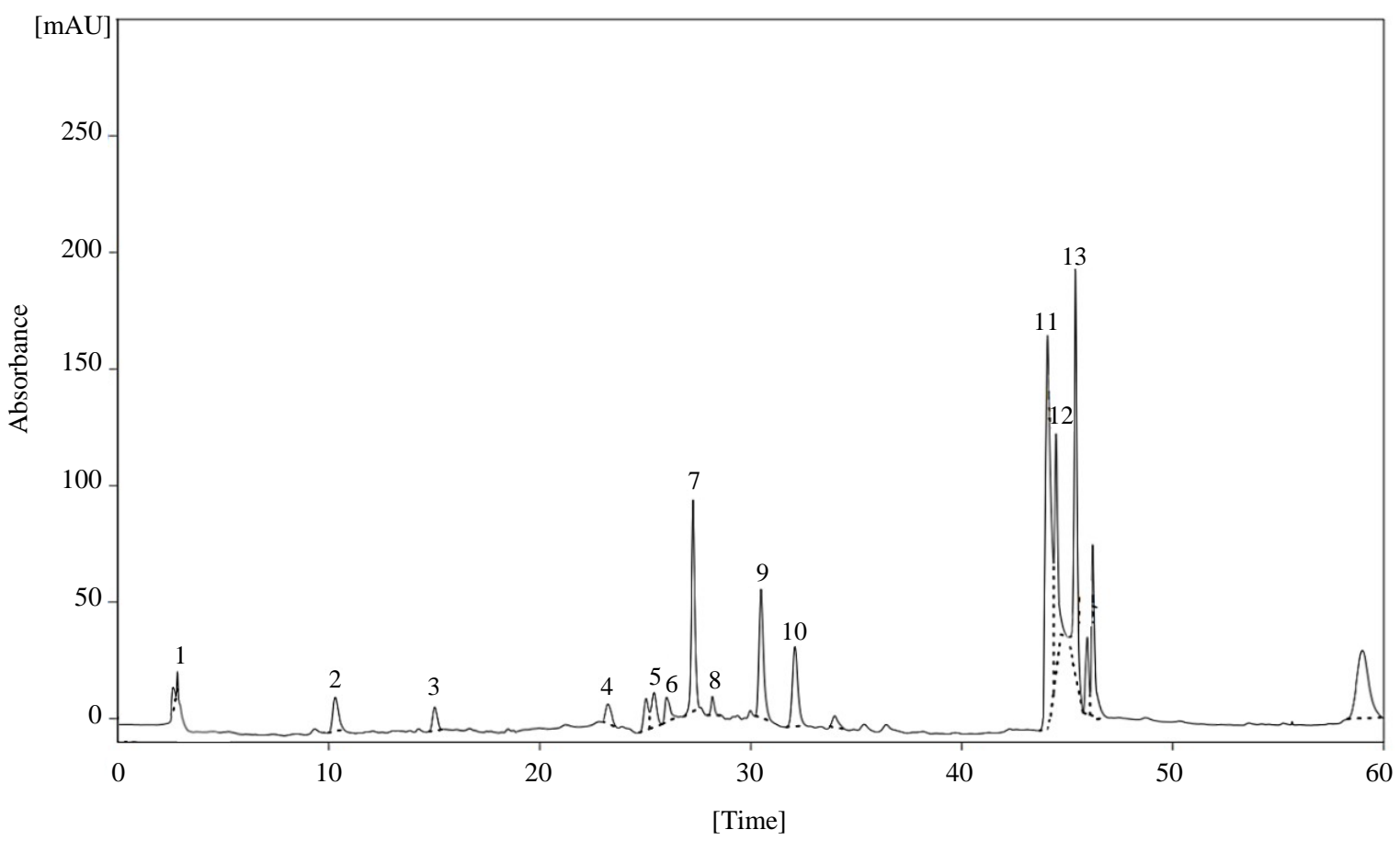

Fig. 2: HPLC chromatogram registered at $280 \mathrm{~nm}$ for the major phenolic compounds detected in the ethanolic extract of C. europaea

\section{Antioxidant Activity}

Caralluma europaea EE and EAE antioxidant activity was evaluated in vitro using two complementary assays: DPPH and reducing power assay.
The concentration that resulted in 50\% inhibition (IC50) are shown in Table 4. The antioxidant activities were compared with that of quercetin,

Ascorbic acid and Butylated hydroxytoluene (BHT). Lower IC50 values indicate stronger antioxidant activity. 
Table 3: The phenols amounts found in the ethanolic extract ranged from 1 to $25 \mathrm{mg}$ EGA/100 $\mathrm{g}$ DM.

\begin{tabular}{lll}
\hline & Phenolic compounds & Concentrations $(\mathrm{mg}$ EGA/100 g DM) \\
\hline 1 & Ascorbicacid & 12,488 \\
2 & Catechicacid & 13,109 \\
3 & Vanilicacid & 12,657 \\
4 & Furrulicacid & 12,698 \\
5 & Caffeicacid & 13,053 \\
6 & Narginine & 12,743 \\
7 & Quinin & 15,993 \\
8 & Vanilin & 12,387 \\
9 & 2-hydroxycinnamic & 15,305 \\
10 & Sinapicacid & 14,489 \\
11 & Catechin & 24,797 \\
12 & P-Coumaric & 16,477 \\
13 & Quercitin & 18,719 \\
\hline
\end{tabular}

Table 4: IC $50(\mu \mathrm{g} / \mathrm{ml})$ values of Caralluma europaea ethanolic and ethyl acetate extracts compared to synthetic antioxidants (Ascorbic acid, quercetin and BHT).

\begin{tabular}{lll}
\hline & DPPH & Reducing power \\
\hline BHT & $2.39 \pm 0.015$ & $2.31 \pm 0.016$ \\
Quercetin & $1.91 \pm 0.023$ & $2.66 \pm 0.054$ \\
Ascorbic acid & $1.81 \pm 0.015$ & $4.05 \pm 0.001$ \\
Ethanolic extract & $34.60 \pm 0.300$ & $79.15 \pm 2.110$ \\
Ethyl acetate extract & $20.60 \pm 0.120$ & $54.95 \pm 1.040$ \\
\hline
\end{tabular}

Table 5: Effect of Caralluma europaea ethanolic (EE) and Ethyl Acetate (EAE) extracts on the acetic acid-induced writhing behavior in mice. Ethanolic and ethyl acetate extracts (D1 $=100 \mathrm{mg} / \mathrm{kg}, \mathrm{D} 2=200 \mathrm{mg} / \mathrm{Kg}$, p.o.) and acetylsalicylic acid $(\mathrm{ASA}=200 \mathrm{mg} / \mathrm{kg}$, i.p.) were administered. Results are presented as mean $\pm \mathrm{SEM} * * * \mathrm{p}<0.001 \mathrm{Vs}$. Control

\begin{tabular}{lll}
\hline Groups & Number of writhes & Percentage of writhes inhibition $(\%)$ \\
\hline Control & $145.0 \pm 17.78$ & $0 \pm 0$ \\
ASA $(200 \mathrm{mg} / \mathrm{kg})$ & $48.2 \pm 6.46 * * *$ & $66.86 \pm 2.84$ \\
EE $(100 \mathrm{mg} / \mathrm{kg})$ & $53.0 \pm 2.58 * * *$ & $62.04 \pm 4.60$ \\
EE $(200 \mathrm{mg} / \mathrm{kg})$ & $51.0 \pm 1.76 * * *$ & $63.00 \pm 4.24$ \\
EAE $(100 \mathrm{mg} / \mathrm{kg})$ & $59.2 \pm 2.87 * * *$ & $57.05 \pm 4.92$ \\
EAE $(200 \mathrm{mg} / \mathrm{kg})$ & $48.6 \pm 3.14 * * *$ & $65.00 \pm 3.27$ \\
\hline
\end{tabular}

Both Caralluma europaea extracts exhibited significant antioxidant activity, the lowest IC50 was obtained with DPPH for the EAE $(\mathrm{IC} 50=20.60 \pm 0.12 \mu \mathrm{g} / \mathrm{mL})$. This activity was less potent than those of reference antioxidants Butylated Hydroxytoluene (BHT), ascorbic acid and quercetin (IC50 values from 1.81 $\pm 0.015 \mu \mathrm{g} / \mathrm{ml}$ to $4.05 \pm 0.001 \mu \mathrm{g} / \mathrm{ml}$ )

\section{Pharmacological Tests}

\section{Writhing Test}

The result in Our results in Table 5 indicated that the ethanolic and ethyl acetate extract (100 and $200 \mathrm{mg} / \mathrm{kg}$. p.o.) significantly decreased the number of writhes induced by acetic acid $(\mathrm{p}<0.001)$. Percentage of writhes inhibition was $63 \%$ for ethanolic extract $(200 \mathrm{mg} / \mathrm{kg}$, p.o.) and $65 \%$ for ethyl acetate extract $(200 \mathrm{mg} / \mathrm{kg}$, p.o.) compared with control $0 \%$. ASA caused remarkable pain inhibition (66.8\%).

\section{Formalin Test}

The intraplantar injection of formalin at $2 \%$ generated a reaction typical of two-phase liking. Pre- treatment with EE and EAE (100 and $200 \mathrm{mg} / \mathrm{kg}$, p.o.) significantly reduced both the early and late phases of formalin nociceptive response in a dose dependent manner compared to the control $(\mathrm{p}<0.01 ; \mathrm{p}<0.001)$. Pretreatment with naloxone failed to reverse the analgesic activity of both extracts in this test (Table 6).

\section{Hotplate Test}

Results of hotplate test showed a highly significant difference between control and EAE ( $p<0.001)$. The EE exhibited no effect on the time latency in the hot plate. Compared to the control, EAE have increased latency time, most notably when higher doses were used $(p<0.001)$. However, EAE in both doses exhibited a lower analgesic effect compared to morphine (Fig. 3a). The use of naloxone significantly reduced the analgesic effect of morphine and the analgesic effect of EAE was not altered by the use of naloxone (Fig. 3b).

\section{Anti-Inflammatory Activity}

Figure 4 shows the effect of Caralluma europaea extracts on the xylene-induced mice ear edema test. After 
xylene induction, a significantly increased formation of edema was observed in control mice. The antiinflammatory activity data indicated that all test concentrations (EE and EAE (100 and $200 \mathrm{mg} / \mathrm{kg})$ ) significantly reduced the xylene-induced edema in comparison to control $(\mathrm{p}<0.001)$, in a dose-dependent manner. However, reduction of the edema by EAE and EE at both doses was less than the standard used (Diclofenac).
As illustrated in Figure 5, histological assessment of the ear tissues showed that the application of xylene induced a marked increase in epidermis thickness, edema and infiltration of Polymorphonuclear (PMN) leukocytes. Oral administration of Caralluma europaea extracts (100 and $200 \mathrm{mg} / \mathrm{kg}$ ) and Diclofenac (10 mg/kg) greatly reduced the indicated changes.

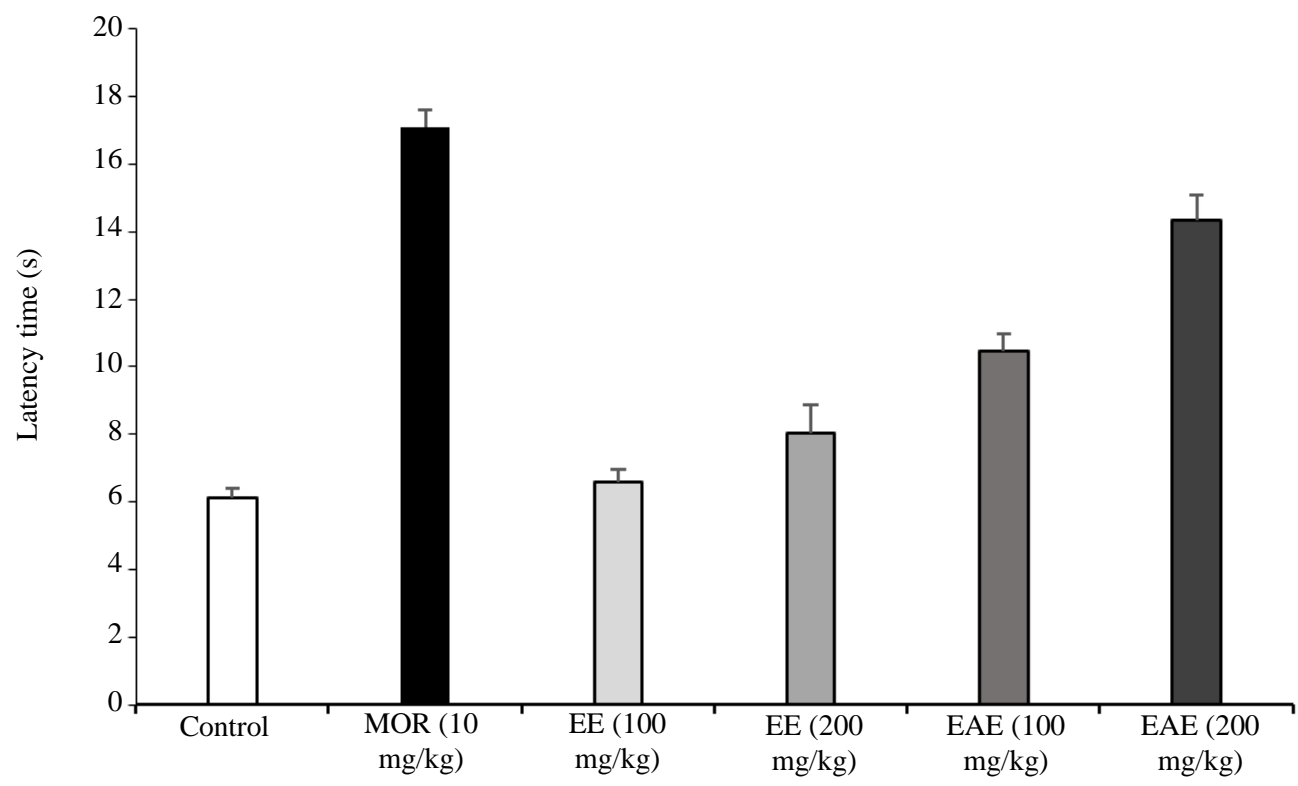

(a)

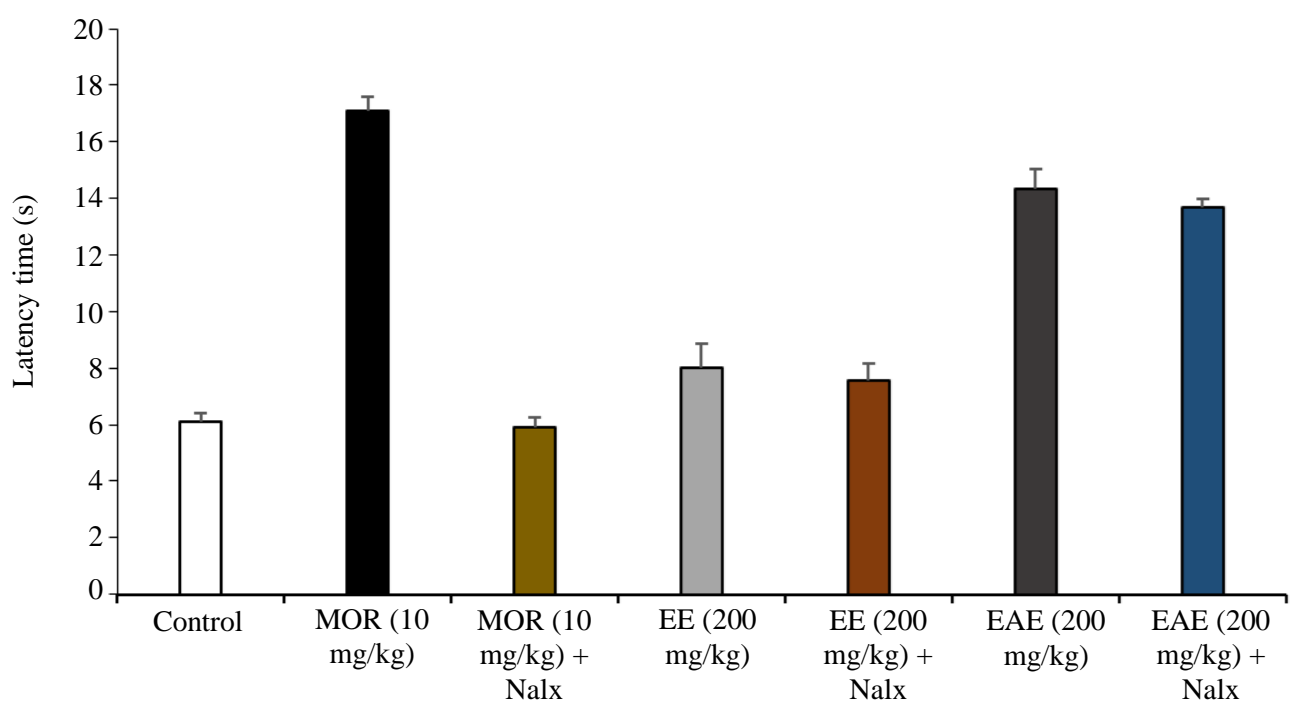

(b)

Fig. 3:Effect of Caralluma europaea ethanolic (EE) and ethyl acetate (EAE) extracts on the nociceptive response in the hot plate test. Caralluma europaea extracts (D1 = $100 \mathrm{mg} / \mathrm{kg}, \mathrm{D} 2=200 \mathrm{mg} / \mathrm{Kg}$, p.o.) were administered $30 \mathrm{~min}$ before testing (a). Results of the hot plate test, in absence and presence of naloxone (Nalx) (1 m/kg, s.c.), EE and EAE extracts (200 mg/kg, p.o.) were administered 30 min before testing (b). Results are presented as mean \pm SEM $* * * p<0.001$ Vs. Control 


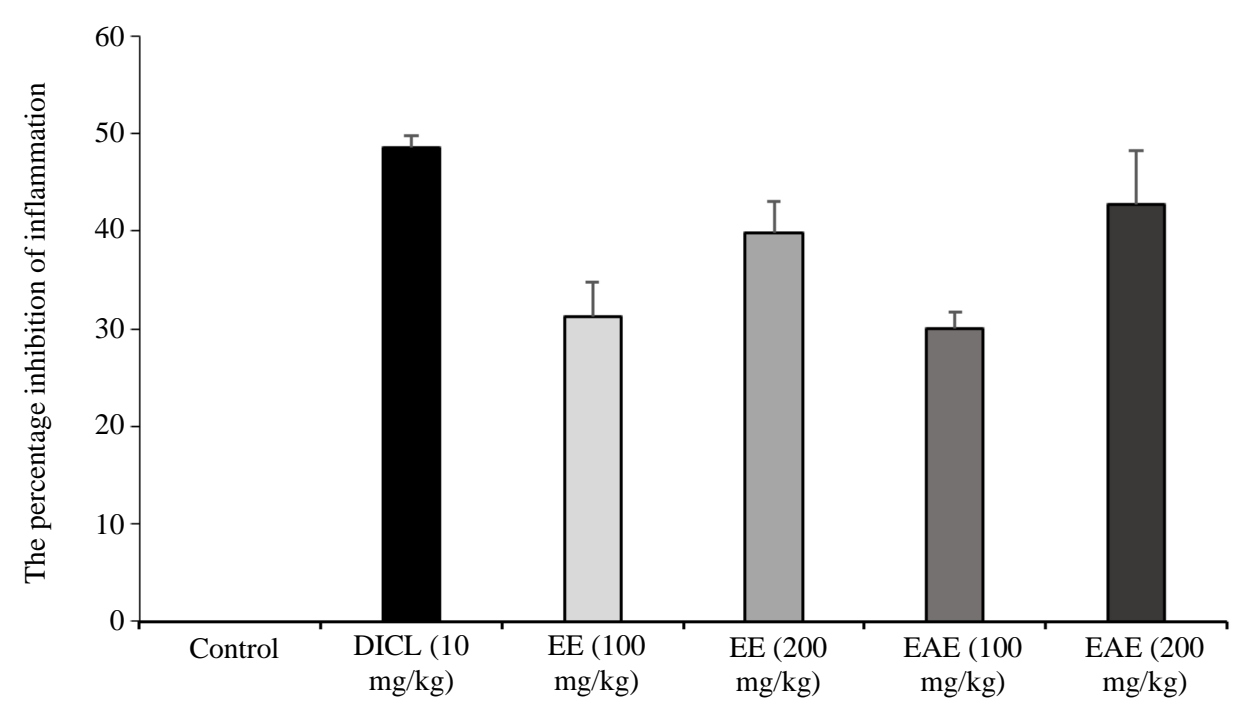

Fig. 4:Effect of ethanolic (EE) and Ethyl Acetate (EAE) extracts on inflammation response in Xylene test. Diclofenac (DICL $=10$ $\mathrm{mg} / \mathrm{kg}$ i.p), ethanolic and ethyl acetate extracts (D1 $=100 \mathrm{mg} / \mathrm{kg}, \mathrm{D} 2=200 \mathrm{mg} / \mathrm{Kg}$, p.o.) were administered $45 \mathrm{~min}$ before Xylene application. Results are presented as mean \pm SEM
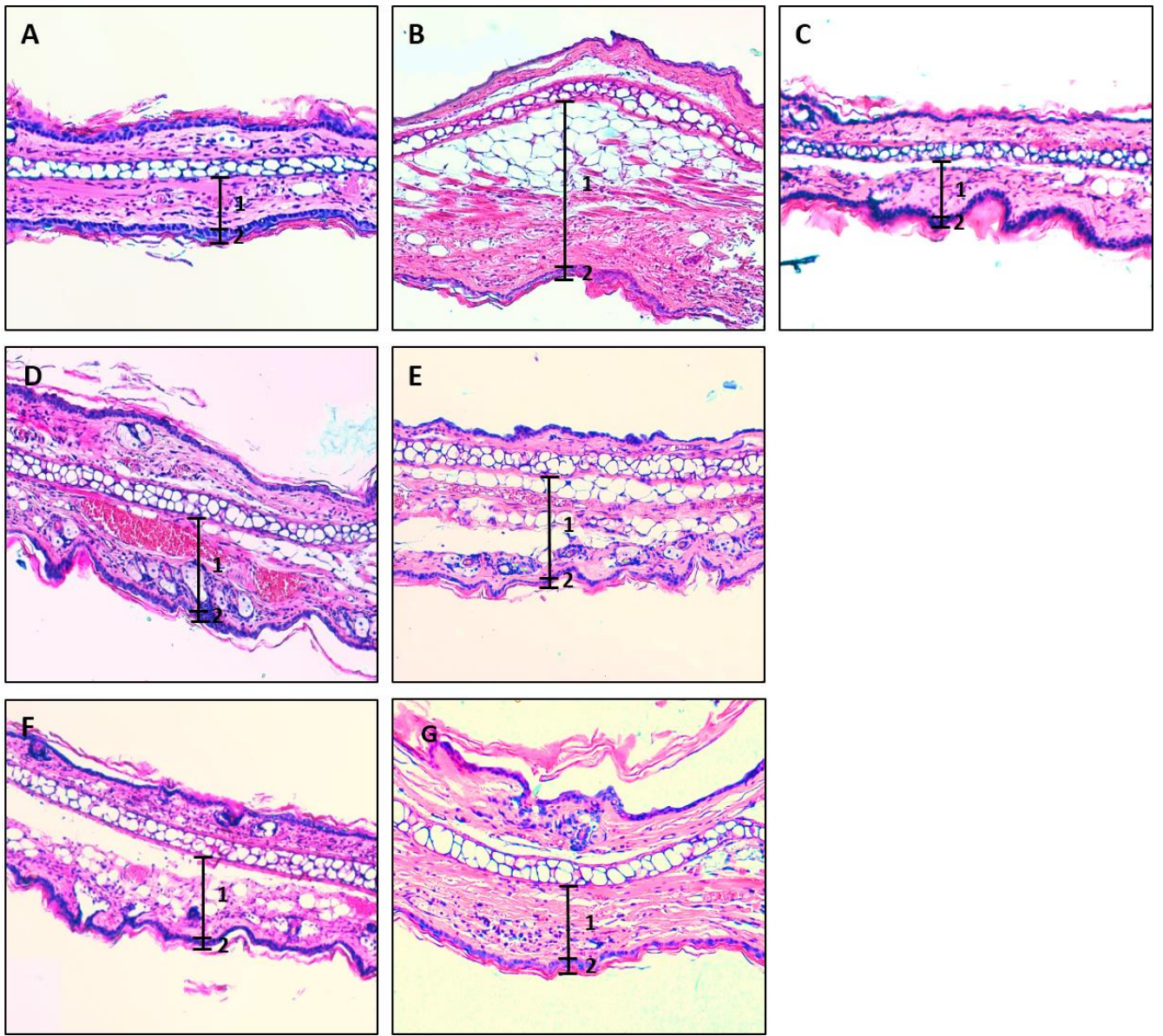

Fig. 5: Histopathological sections showing ear swelling induced by xylene treatment. (A) Normal ear; (B) xylene-induced model control group; (C) treatment with Diclofenac (10 mg/kg); (D) treatment with Ethanolic Extract (100 mg/kg); (E) treatment with Ethyl Acetate Extract (100 mg/kg); (F) treatment with Ethanolic Extract $(200 \mathrm{mg} / \mathrm{kg})$; and (G) treatment with Ethyl Acetate Extract $(200 \mathrm{mg} / \mathrm{kg})$. 1: Dermal thickness; 2: Epidermis thickness. $(\mathrm{HE} \times 100)$ 
Table 6: The antinociceptive effect of Caralluma europaea extracts (EE and EAE), Morphine (MOR), Acetylsalicylic Acid (ASA) and reversal effect of naloxone (Nalx) on formalin-induced pain in mice. Values are represented as the mean \pm SEM. Differences between groups were statistically analyzed by ANOVA followed by Tukey's multiple range test. ${ }^{* *} \mathrm{p}<0.01$; $* * * \mathrm{p}<0.001 \mathrm{Vs}$. Control

\begin{tabular}{llc}
\hline & Total time spent in licking $(\mathrm{s})$ & \\
Group & $-1^{\text {st }}$ phase & $2^{\text {nd }}$ phase \\
\hline Control & $122.47 \pm 8.84$ & $179.51 \pm 5.15$ \\
EE $(100 \mathrm{mg} / \mathrm{kg})$ & $90.54 \pm 7.93 * *$ & $65.77 \pm 0,06 * * *$ \\
EE $(200 \mathrm{mg} / \mathrm{kg})$ & $86.83 \pm 4.37 * *$ & $42.16 \pm 6.70^{* * *}$ \\
EE $(200 \mathrm{mg} / \mathrm{kg})+\mathrm{Nalx}$ & $87.23 \pm 9.50^{* *}$ & $44.81 \pm 8.87 * * *$ \\
EAE $(100 \mathrm{mg} / \mathrm{kg})$ & $93.34 \pm 4.33 * *$ & $51.974 \pm 0.13 * * *$ \\
EAE $(200 \mathrm{mg} / \mathrm{kg})$ & $72.26 \pm 5.34 * * *$ & $47.33 \pm 0.52 * * *$ \\
EAE $(200 \mathrm{mg} / \mathrm{kg})+\mathrm{Nalx}$ & $73.81 \pm 3.43 * * *$ & $57.53 \pm 0.53 * * *$ \\
MOR $(10 \mathrm{mg} / \mathrm{kg})$ & $49.91 \pm 3.47 * * *$ & $30.01 \pm 3.21 * * *$ \\
MOR $(10 \mathrm{mg} / \mathrm{kg})+\mathrm{Nalx}$ & $134.01 \pm 8.40$ & $195.18 \pm 10.42$ \\
ASA $(200 \mathrm{mg} / \mathrm{kg})$ & $113.83 \pm 4.90$ & $39.09 \pm 1.61 * * *$ \\
\hline
\end{tabular}

\section{Discussion}

Our study aims to assess the pharmacological proprieties of Caralluma europaea, which are currently used in Moroccan traditional medicine to treat cyst and goiter (Bellakhdar, 1997). Other studies have reported the biological activity of extracts obtained from many species of the genus Caralluma such as antihyperglycemic, hepatoprotective, anti-inflammatory and antinociceptive proprieties (Chinenye et al., 2013; Shanmugam et al., 2013; Abdel-Sattar et al., 2013). In our study, to evaluate the analgesic and antiinflammatory potency of Caralluma europaea's ethanolic and Ethyl Acetate (EE and EAE) extracts. Four experiences were conducted.

Indeed, the tests used for analgesic study are: First, the writhing test was conducted to examine the peripheral analgesic effect. Second, the hot plate test to assess the involvement of central mechanisms, which was known to activate supraspinal and nociceptive spinal pathways (Paulino et al., 2003, Arslan and Bektas, 2010). Third, the formalin test was used to explore peripheral and central mechanisms (Tjølsen et al., 1992).

In addition, to differentiate between central and peripheral antinociceptive effect of $\mathrm{EE}$ and EAE, naloxone was administered with both extracts. Naloxone is an antagonist of the opioid receptors that blocks the central antinociceptive effect of analgesics/opioids.

Usually the acetic acid-induced writhing test is mainly used to examine the antinociceptive activity of biological components (Khan et al., 2010; Ibrar et al., 2012). The release of several endogenous noxious mediators such as serotonin, histamine, bradykinin and substance $\mathrm{P}$ is produced by acetic acid. The contraction of the abdominal muscles is associated with the lengthening of the body and the extension of the forelegs that characterize the pain caused by acetic acid (Ibrar et al., 2012). Local peritoneal receptors as well as prostaglandin pathways are assumed to be involved for abdominal contraction (Al-Harrasi et al., 2014). In this study, EE and EAE extracts entrained a significant dosedependent analgesic effect in writhing test. This effect was especially high when EAE administrated at 200 $\mathrm{mg} / \mathrm{kg}$ dose. The antinociceptive activity observed after oral administration of Caralluma europaea EE and EAE can occur because of blocking of prostaglandin pathways or inhibition of endogenous mediators.

The hot-plate test is a pain test in which opioid or central analgesics apply their analgesic effects via supraspinal and spinal receptor (Abbott and Melzack, 1982). Results of this test show that, morphine group present a significant antinociceptive effect. Oral administration of EAE extracts also a strong analgesic effect in this model. However, the use of naloxone has completely reversed the antinociceptive effect of morphine, while antinociceptive action of EAE was not reversed by the opioid antagonist, naloxone. So, the mechanism (s) underlying the antinociceptive action of the extract in both hot-plate and formalin tests appear to be unrelated to the opioid system.

In order to confirm the antinociceptive activity of our extracts, the formalin test was selected. Results showed that the time spent in licking the injured paw was significantly reduced by oral administration of EE and EAE in both phases. The EAE was highly efficient at $200 \mathrm{mg} / \mathrm{kg}$ dose than the EE. Our results show also that peripheral acting drug, acetylsalicylic acid, reduce nociception only in the late phase by inhibiting the inflammatory process (Hunskaar and Hole, 1987; Rosland et al., 1990). These results suggest that EE and EAE have analgesic action at the central and peripheral levels.

The possible antinociceptive activity may be linked to the high polyphenol content of plants, especially flavonoids and tannins (Handa et al., 1992; Orhan et al., 2007). Whose were noted in our study (Table 1). It is well established that flavonoids have an analgesic activity on the acetic acid-induced writhing test 
(Calixto et al., 2000; Ahmed et al., 2007). The analgesic effect mechanism of the extracts in our study can be related to the process implicated in inhibiting nociceptor sensitization, blocking nociceptors (peripheral and/or central) or regulating sensitized nociceptors (Ferreira et al., 1990). Some biochemical studies on the mechanism of action of flavonoids have revealed that these compounds can block a large range of enzymes implicated in the synthesis of prostaglandins. The polyphenols found in this plant, such as quercetin, can be responsible for the analgesic activities observed.

The acute inflammation induced by xylene in the mouse ear has been used in general as a classic method to detect the effects of anti-inflammatory agents (Hossein Zadeh and Younesi, 2002; Kou et al., 2005). The study in this paper examined the impacts of Caralluma europaea EE and EAE on acute xyleneinduced inflammation. After topical application of xylene, significant increases in ear weight were detected due to the acute inflammatory response; these increases in ear weight were used as valuable indicators for antiinflammatory effects (Al-Majed et al., 2003; Ojewole, 2005). In this study, the increase in ear weight was inhibited on a dose-dependent basis by pre-treatment with our extracts and Diclofenac (Non-Steroidal AntiInflammatory Drug). Histopathologically, severe vasodilation, inflammatory cell infiltration and edematous skin changes were detected as signs of acute inflammation after application of xylene (Puerta et al., 1996; Kou et al., 2003; Rotelli et al., 2003); as a consequence of these histopathological changes, ear tissue thickness was markedly increased. However, there were dose-dependent decreases in these histopathological changes and ear tissue thickness after pre-treatment with Caralluma europaea EE and EAE extracts. This inhibition has been considered as direct evidence that the two extracts used in this study have positive effects on the reduction of the acute inflammatory response, comparable to those of Diclofenac. The known anti-inflammatory action of this NSAID is the inhibition of the cyclooxygenase activity (Miura et al., 1993; El-Banhawy et al., 1993; Mc Cafferty et al., 1995; Waterbury et al., 2006). This was confirmed by the observed reductions in weight and skin thickness and by the improvement of several histopathological indicators.

The anti-inflammatory activity of our extracts could be attributed to its phytochemical compounds such as polyphenols. Several plants rich in polyphenols, particularly flavonoids, are believed to have important pharmacological activities, such as antioxidant, antiinflammatory, muscle relaxant and antinociceptive actions (Meotti et al., 2006; Fernandez et al., 2009).

Furthermore, in several studies, flavonoids like rutin, quercetin, sinapic acid, p-coumaric acid, 2hydroxycinnamic and catechin yielded important anti- inflammatory and analgesic activities (Nagasaka et al., 2007; Nakanishi et al., 2010; Ramesh et al., 1998; Bittar et al., 2009; Farahpour, 2014). Accordingly, HPLC analysis had shown high amounts of these phenolic components especially in the Caralluma europaea EAE extract.

Numerous reports indicate that antioxidants are able to reduce pain and inflammation produced by chemical and thermal excitation (Hacimuftuoglu et al., 2006). In normal conditions, there is an equilibrium of the free radical-antioxidant system. However, the impairment in the free radical-antioxidant profile induces cellular and tissue damage known as oxidant damage (Karaca et al., 2006). In our study, the protective role of Caralluma europaea EAE and EE against oxidative stress was evaluated by using DPPH free radical-scavenging activity and reducing power assay. Our results are in line with the results reported by Ait Dra et al. (2018) on the methanolic extract of Caralluma europaea.

Reducing power is an antioxidant mechanism of action and can serve as an indicator of the potential antioxidant activity of new drugs (Jayaprakash et al., 2001). Many studies have demonstrated that the antioxidant effect is linked to the development of reductions (Yen and Duh, 1994). Thus, in the present study, the antioxidant activity of Caralluma europaea extracts can be combined with its reducing power.

According to Rekka and Kourounakis (1991), the scavenging of DPPH radical is related to the lipid peroxidation inhibition. In addition, the work of Kaviarasan et al. (2007) showed that the DPPH radical involves a process of transferring hydrogen atoms. in this assay, the antioxidant activity on DPPH radical of EAE and EE extracts can be attributed to a direct role in trapping free radicals by donating hydrogen atom.

This study brought a demonstration of antioxidant, analgesic and anti-inflammatory activities by Caralluma europaea ethanolic and ethyl acetic extracts. Although, to date, the precise mechanism underlying the antinociceptive and anti-inflammatory action of Caralluma europaea remains unclear, this plant, rich in bioactive polyphenols might be of potential interest in the future development of new clinically relevant drugs for the management of pain and inflammation.

\section{Conclusion}

Our study revealed that complementary analgesic and anti-inflammatory activities of the ethanolic and ethyl acetic extracts of Caralluma europaea, can be related and mediated by its antioxidant activity. This justifies at least the ethnomedical uses of this plant. Although they lack other studies, such as in vivo antioxidant activity and chronic toxicity studies, this plant could have a potential interest in the development of new drugs for pain and inflammation management. 


\section{Acknowledgement}

Authors would like to thank M. Ait Laaradia, S. Oufquir for their participation in the realization of hitological sections, A. Regragui for his help providing animals and drugs; and we would also like to thank deeply E. Gaylard for her time and effort to revise the scientific English.

\section{Authors Contributions}

All authors participated in all experiments, coordinated the data-analysis and contributed to the writing of the manuscript.

\section{Conflict of Interest}

The authors report no declarations of interest.

\section{Ethics}

This article is originally from the authors works. The corresponding author confirms that all of the other authors have read and approved the manuscript and no ethical issues involved.

\section{References}

Abbott, F.V. and R. Melzack, 1982. Brainstem lesions dissociate neural mechanisms of morphine analgesia in different kinds of pain. Brain Res., 251: 149-155. DOI: 10.1016/0006-8993(82)91282

Abdel-Sattar, E.A., H.M. Abdallah, A. Khedr, A.B. Abdel-Naim and I.A. Shehata, 2013. Antihyperglycemic activity of Carallumatuberculata in streptozotocin-induced diabetic rats. Food Chemical Toxicol., 59: 111-117. DOI: $10.1016 /$ j.fct.2013.05.060

Ahmed, A., N. Ilyas, H. Ibrahim, K.Y. Musa and A.H. Yaro, 2007. Analgesic effects of Tacazzeaapiculataoliv. Nigerian J. Pharmaceutical Sci., 2: 134-138.

Ait Dra, L., S. Sellami, H. Rais, F. Aziz and A. Aghraz et al., 2018. Antidiabetic potential of Caralluma europaea against alloxan-induced diabetes in mice. Saudi J. Biol. Sci., 26: 1171-1178.

DOI: $10.1016 /$ j.sjbs.2018.05.028

Al-Harrasi, A., L. Ali, J. Hussain, N.U. Rehman and Mehjabeen et al., 2014. Analgesic effects of crude extracts and fractions of Omani frankincense obtained from traditional medicinal plant Boswellia sacra on animal models. Asian Pacific J. Tropical Med., 7: S485-S490.

DOI: 10.1016/S1995-7645(14)60279-0
Al-Jadidi, H.S.K. and M.A. Hossain, 2018. Studies on total phenolics, total flavonoids and antimicrobial potential from the leaves crude extracts of neem traditionally used for the treatment of cough and nausea. J. Basic Applied Sci., 4: 93-98.

DOI: 10.1016/j.bjbas.2015.05.001

Al-Majed, A.A., M. Khattab, M. Raza, O.A. AlShabanah and A.M. Mostafa, 2003. Potentiation of diclofenac-induced anti-inflammatory response by aminoguanidine in carrageenan-induced acute inflammation in rats: the role of nitric oxide. Inflamm Res., 52: 378-82.

DOI: $10.1007 / \mathrm{s} 00011-003-1189-1$

Arslan, R. and N. Bektas, 2010. Antinociceptive effect of methanol extract of Capparis ovata in mice. Pharm. Biol., 48: 1185-90.

DOI: $10.3109 / 13880201003629323$

Badakhshan, M.P., L.J. Subramanion, Y.L. Lachimanan, C. Yeng. and S. Sreenivasan, 2012. Antioxidant activity of methanol extracts of different parts of Lantana camara. Asian. Pac. J. Trop. Biomed., 2: 960-965. DOI: 10.1016/S2221-1691(13)60007-6

Bellakhdar, J., 1997. La Pharmacopée Marocaine Traditionnelle: Médecine Arabe Ancienne et Savoirs Populaire. 1st Edn., Ibis Press, France, ISBN-13: 9782910728038.

Bittar, M., M.M. De Souza, R.A. Yunes, R. Lento and F. Delle Monache et al., 2009. Antinociceptive activity of I3, II8-binaringenin, a biflavonoid present in plants of the Guttiferae. Planta Med., 66: 84-86. DOI: $10.1055 / \mathrm{s}-0029-1243118$

Brennan, M., 1984. Adverse effects of NSAIDs on renal function. Canadian Med. Assoc. J., 131: 1012-1013.

Bürger, C., D.R. Fischer, D.A. Cordenunzzi, A.P. Batschauer de Borba and V.C. Filho et al., 2005. Acute and subacute toxicity of the hydroalcoholic extract from Wedelia paludosa (Acmelabrasilinsis) (Asteraceae) in mice. J. Pharmaceutical Sci., 8: 370-373.

Burits, M. and F. Bucar, 2000. Antioxidant activity of Nigella sativa essential oil. Phytother. Res., 14: 323328. DOI: 10.1002/10991573(200008)14:5<323::AID-PTR621>3.0.CO;2-Q

Calixto, J.B., A. Beirith, J. Ferreira, A.R. Santos and V.C. Filho et al., 2000. Naturally occurring antinociceptive substances from plant. Phytotherapy Res., 14: 401-418. DOI: 10.1002/10991573(200009)14:6<401::AID-PTR762>3.0.CO;2-h

Chinenye, J.U.O., K. Abubakar, M.O. Ugwah and A.A. Njan, 2013. Evaluation of the antinociceptive and anti-inflammatory effect of Carallumadalzielii. J. Ethnopharmacol., 150: 967-972.

DOI: 10.1016/j.jep.2013.09.049 
De Miranda, G.F.B., J.C. Vilar, I.A. Nunes Alves, S.C.H. Cavalcanti and A.R. Antoniolli, 2001. Antinociceptive and antiedematogenic properties and acute toxicity of Tabebuia avellendaelor. Ex griseb. Inner bark aqueous extracts. B.M.C. Pharmacol., 1: 6-6. DOI: 10.1186/1471-2210-1-6

Dutt, H.C., S. Singh, B. Avula, I.A. Khan and Y.S. Bedi, 2012. Pharmacological review of Caralluma R.Br. with special reference to appetite suppression and anti-obesity. J. Med. Food., 15: 108-119.

DOI: $10.1089 /$ jmf.2010.1555

El-Banhawy, M.A., S.M. Sanad, S.A. Sakr, I.A. ElElaimy and H.A. Mahran, 1993. Histopathological studies on the effect of the anticoagulantrodenticide "Brodifacoum" on the liver of rat. J. Egypt. Ger. Soc. Zool., 12: 185-227.

Ezeja, M.I., Y.S. Omeh, I.I. Ezeigbo and A. Ekechukwu, 2011. Evaluation of the analgesic activity of the methanolic stem bark extract of Dialium guineense (Wild). Annals Med. Health Sci. Res., 1: 55-62.

Fan, S., N.A. Ali and D.F. Basri, 2014. Evaluation of analgesic activity of the methanol extract from the galls of Quercus infectoria (Olivier) in rats. Evidence-Based Complementary Alternative Med., 2014: 976764-976764. DOI: 10.1155/2014/976764

Farahpour, M.R., 2014. Antioxidant activity, antinociceptive and anti-inflammatory effects of pot marigold hydroalcoholic extract on experimental animals. Int. J. Pharmacol. Technical Res., 6: 1640-1646.

Farouk, L., A. Laroubi, A. Aboufatima, A. Benharref and A. Chait, 2008. Evaluation of the analgesic effect of alkaloid extract of Peganum harmala L.: Possible mechanisms involved. J. Ethnopharmacol., 115: 449-454. DOI: 10.1016/j.jep.2007.10.014

Fernandez, S.P., M. Nguyen, T.T. Yow, C. Chu and G.A. Johnston et al., 2009. The flavonoid glycosides, myricitrin, gossypin and naringin exert anxiolyticaction in mice. Neurochem. Res., 34: 1867-1875. DOI: 10.1007/s1 1064-009-9969-9

Ferreira, A., C. Proenc, M.L.M. Serralheiro and M.E.M. Ara'ujo, 2006. The in vitro screening for acetylcholinesterase inhibition and antioxidant activity of medicinal plants from Portugal. J. Ethnopharmacol., 108: 31-37. DOI: 10.1016/j.jep.2006.04.010

Habashy, R.R., A.B. Abdel-Naim, A.E. Khalifa and M.M. Al-Azizi, 2005. Anti-inflammatory effects of jojoba liquid wax in experimental models. Pharmacol. Res., 51: 95-105. DOI: 10.1016/j.phrs.2004.04.011

Hacimuftuoglu, A., C.R. Handy, V.M. Goettl, C.G. Lin and S. Dane et al., 2006. Antioxidants attenuate multiple phases of formalin-induced nociceptive response inmice. Behav. Brain Res., 173: 211-216. DOI: 10.1016/j.bbr.2006.06.030
Handa, S.S., A.S. Chawla and A.K. Sharma, 1992. Plants with anti-inflammatory activity. Fitoterapia, 63: 3-31.

Hossein Zadeh, H. and H.M. Younesi, 2002. Antinociceptive and antiinflammatory effects of Crocus sativus L. stigma and petal extracts in mice. B.M.C. Pharmacol., 15: 2-7.

Hunskaar, S. and K. Hole, 1987. The formalin test in mice: Dissociation between inflammatory and noninflammatory pain. Pain, 30: 103-114. DOI: 10.1016/0304-3959(87)90088-1

Ibrar, M., N. Muhammad, Barkatullah., H. Khan and F. Jahan et al., 2012. Antinociceptive and anticonvulsant activities of essential oils of Zanthoxylum armatum. Phytopharmacology, 3: 191-198.

Jayaprakash, G.K., R.P. Singh and K.K. Sakariah, 2001. Antioxidant activity of grape seed (Vitis vinifera) extracts on peroxidation models in-vitro. J. Agric. Food Chem., 73: 285-290.

DOI: $10.1016 / \mathrm{S} 0308-8146(00) 00298-3$

Karaca, S., M. Kulac, E. Uz, H. Mollaoglu and R. Y1lmaz, 2006. Erythrocyte oxidant/antioxidantstatus in essential hyperhidrosis. Molecular Cellular Biochem., 290: 131-135. DOI: 10.1007/s11010-006-9177-8

Kaviarasan, S., G.H. Naik, R. Gangabhagirathi, C.V. Anuradha and K.I. Priyadarsini, 2007. In vitro studies on antiradical and antioxidant activities of fenugreek (Trigonellafoenum graecum) seeds. Food Chem., 103: 31-37. DOI: 10.1016/j.foodchem.2006.05.064

Khan, H., M. Saeed, A.U. Gilani, M.A. Khan and A. Dar et al., 2010. The antinociceptive activity of Polygonatum verticillatum rhizomes in pain models. J. Ethnopharmacol., 127: 521-527. DOI: $10.1016 /$ j.jep.2009.10.003

Kiernan, J.A., 1999. Histological and Biochemical Methods: Theory and Practice. 3rd Edn., Butterworth Heinmann, Oxford.

Kou, J., Y. Ni, N. Li, J. Wang and L. Liu et al., 2005. Analgesic and anti-inflammatory activities of total extract and individual fractions of Chinese medicinal ants Polyrhachis lamellidens. Biol. Pharm. Bull., 28: 176-180. DOI: $10.1248 / \mathrm{bpb} .28 .176$

Kou, J.M., R.M. Ma, D.M. Zhu and Y. Yan, 2003. Blood-activating anti-inflammatory actions of Polygala fallax. Zhong Yao Cai. Eur. PMC, 26: 268-271. PMID: 14528694

Mc Cafferty, D., D.N. Granger and J.L. Wallace, 1995. Indomethacin-induced gastric injury and leukocyte adherence in arthritic versus healthy rats. Gastroenterology, 109: 1173-1180. DOI: 10.1016/0016-5085(95)90576-6

Meotti, F.C., A.P. Luiz, M.G. Pizzolatti, C.A. Kassuya and J.B. Calixto et al., 2006. Analysis of the antinociceptive effect of the flavonoid myricitrin: Evidence for a role of the L-arginine-nitric oxide and protein kinase $\mathrm{C}$ pathways. J. Pharmacol. Exp. Therapeut., 316: 789-796. DOI: $10.1124 /$ jpet.105.092825 
Meve, U. and S. Heneidak, 2005. A morphological, karyological and chemical study of the Apteranthes (Caralluma) Europaea complex. Biol. J. Linnean Society, 149: 419-432.

DOI: $10.1111 / \mathrm{j} .1095-8339.2005 .00448 . x$

Meve, U. and S. Liede, 2004. Subtribal division of Ceropegieae (Apocynaceae-Asclepiadoideae). Taxon, 53: 61-72. DOI: 10.2307/4135489

Miura, S., M. Suematsu, S. Tanaka, H. Nagata and S. Houzawa et al., 1991. Microcirculatory disturbance in indomethacin-induced intestinal ulcer. Am. J. Physiology-Gastrointestinal Liver Physiol., 261: G213-G219.

DOI: 10.1152/ajpgi.1991.261.2.G213

Murugesan, D. and R. Deviponnuswamy, 2014. Potential anti-inflammatory medicinal plantsa review. Int. J. Pharmacy Pharmaceutical Sci., 6: 43-49.

Nagasaka, R., C. Chotimarkorn, I.M. Shafiqul, M. Hori and H. Ozaki et al., 2007. Anti-inflammatory effects of hydroxycinnamic acid derivatives. Biochem. Biophys. Res. Commun., 358: 615-619.

DOI: 10.1016/j.bbrc.2007.04.178

Nakanishi, T., K. Mukai, H. Yumoto, K. Hirao and Y. Hosokawa et al., 2010. Anti-inflammatory effect of catechin on cultured human dental pulp cells affected by bacteria-derived factors. Eur. J. Oral Sci., 118: 145-50.

DOI: 10.1111/j.1600-0722.2010.00714.x

Ojewole, J.A., 2005. Antinociceptive, anti-inflammatory and antidiabetic effects of Bryophyllum pinnatum (Crassulaceae) leaf aqueous extract. J. Ethnopharmacol., 99: 13-19.

DOI: $10.1016 /$ j.jep.2005.01.025

Ordoñez, A.A.L., J.D. Gomez, M.A. Vattuone and M.I. Isla, 2006. Antioxidant activities of Sechium edule (Jacq.) Swartz extracts. Food Chem., 97: 452-458. DOI: 10.1016/j.foodchem.2005.05.024

Orhan, D.D., A. Hartevioglu, E. Kupeli and E. Yesilada, 2007. In vivo anti-inflammatory andanti-nociceptive activity of the crude extract and fractions from Rosa canina $L$. fruits. J. Ethnopharmacol., 112: 394-400. DOI: $10.1016 /$ j.jep.2007.03.029

Oyaizu, M., 1986. Studies on product of browning reaction prepared from glucose amine. Japanese J. Nutrit. Dietet., 44: 307-315.

DOI: 10.5264/eiyogakuzashi.44.307

Paulino, N., A.P. Dantas, V. Bankova, D.T. Longhi and A. Scremin et al., 2003. Bulgarian propolis induces analgesic and anti-inflammatory effects in mice and inhibits in vitro contraction of airway smooth muscle. J. Pharmacol. Sci., 93: 307-313.

DOI: $10.1254 /$ jphs.93.307
Puerta, D.L., R.E. Martinez, L. Bravo and M.C. Ahumada, 1996. Effect of silymarin on different acute inflammation models and on leukocyte migration. J. Pharmacy Pharmacol., 48: 968-770. DOI: 10.1111/j.2042-7158.1996.tb06014.x

Ramesh, M., Y.N. Rao, A.V. Rao, M.C. Prabhakar and C.S. Rao et al., 1998. Antinociceptive and antiinflammatory activity of a flavonoid isolated from Caralluma attenuata. J. Ethnopharmacol., 62: 63-36. DOI: 10.1016/S0378-8741(98)00048-8

Rekka, E. and P.N. Kourounakis, 1991. Effect of hydroxyethyl rutosides and related compounds on lipid peroxidation and free radical scavenging activity. Some structural aspects. J. Pharmacy Pharmacol., 43: 486-491.

DOI: 10.1111/j.2042-7158.1991.tb03519.x

Rosland, J.H., A. Tjølsen, B. Mæhle and K. Hole, 1990. The formalin test in mice: Effect of formalin concentration. Pain, 42: 235-242.

DOI: 10.1016/0304-3959(90)91167-H

Rotelli, A.E., T. Guardia and A.O. Juarez, 2003. Comparative study of flavonoids in experimental models of inflammation. Pharmacol. Res., 48: 601-606. DOI: 10.1016/S1043-6618(03)00225-1

Shah Ayub, M.A., S.K. Garg and K.M. Garg, 1997. Subacute toxicity studies on Pendimethalin in rats. Ind. J. Pharmacy, 29: 322-324.

Shang, X., J. Wang, M. Li, X. Miao and H. Pan et al., 2011. Antinociceptive and anti-inflammatory activities of Phlomisumbrosa Turcz extract. Fitoterapia, 82: 716-721.

DOI: $10.1016 /$ j.fitote.2011.03.001

Shanmugam, G., M. Ayyavu, D. Muralidhara Rao, T. Devarajan and G. Subramaniam, 2013. Hepatoprotective effect of Caralluma umbellate against acetaminophen induced oxidative stress and liver damage in rat. J. Pharm. Res., 6: 342-345. DOI: 10.1016/j.jopr.2013.03.009

Singleton, V.L., R. Orthofer and R.M. LamuelaRaventós, 1999. Analysis of total phenols and other oxidation substrates and antioxidants by means of Folin-Ciocalteu reagent. Meth. Enzymol., 299: 152-178. DOI: 10.1016/S0076-6879(99)99017-1.

Tjølsen, A., O.G. Berge, S. Hunskaar, J.H. Rosland and K. Hole, 1992. The formalin test: An evaluation of the method. Pain, 51: 5-17. DOI: 10.1016/0304-3959(92)90003-T.

Waterbury, L.D., D. Silliman and T. Jolas, 2006. Comparison of cyclooxygenase inhibitory activity and ocular anti-inflammatory effects of ketorolac tromethamine and bromfenac sodium. Curr. Med. Res Opin., 22: 1133-1140. DOI: $10.1185 / 030079906 X 112471$ 
Wen, S., Y. Chen, Y. Lu, Y. Wang and L. Ding et al., 2016. Cardenolides from the Apocynaceae family and their anticancer activity. Fitoterapia, 112: 74-84. DOI: $10.1016 /$ j.fitote.2016.04.023

Xu, B.J. and S.K. Chang, 2007. A comparative study on phenolic profiles and antioxidant activities of legumes as affected by extraction solvents. J. Food Sci., 72: 159-166.

DOI: $10.1111 /$ j.1750-3841.2006.00260.x
Yen, G.C. and P.D. Duh, 1994. Scavenging effect of methanolic extracts of peanut hulls on free-radical and active-oxygen species. J. Agric. Food Chem., 42: 629-632. DOI: 10.1021/jf00039a005

Zito, P., M. Sajeva, M. Bruno, A. Maggio and S. Rosselli et al., 2010. Essential oil composition of stems and fruits of Caralluma europaea N.E.Br. (Apocynaceae). Molecules, 15: 627-38.

DOI: 10.3390/molecules15020627 